\title{
Human Body Dynamics
}




\section{Springer}

New York

Berlin

Heidelberg

Barcelona

Hong Kong

London

Milan

Paris

Singapore

Tokyo 
Aydın Tözeren

\section{Human Body Dynamics}

Classical Mechanics and Human Movement

With 177 Illustrations 


\section{Aydin Tözeren}

Department of Biomedical Engineering

The Catholic University of America

Washington, DC 20064

USA

tozeren@cua.edu

Illustrations by Dr. Rukmini Rao Mirotznik. Cover photo ( copyright

Laurie Rubin/The Image Bank.

Library of Congress Cataloging-in-Publication Data

Tözeren, Aydın.

Human body dynamics : classical mechanics and human movement /

Aydın Tözeren.

p. $\mathrm{cm}$.

Includes bibliographical references and index.

ISBN 0-387-98801-7 (alk. paper)

1. Human mechanics. I. Title.

QP303.T69 1999

$612.7^{\prime} 6-\mathrm{dc} 21$

99-15365

Printed on acid-free paper.

(C) 2000 Springer-Verlag New York, Inc.

All rights reserved. This work may not be translated or copied in whole or in part without the written permission of the publisher (Springer-Verlag New York, Inc., 175 Fifth Avenue, New York, NY 10010, USA), except for brief excerpts in connection with reviews or scholarly analysis. Use in connection with any form of information storage and retrieval, electronic adaptation, computer software, or by similar or dissimilar methodology now known or hereafter developed is forbidden.

The use of general descriptive names, trade names, trademarks, etc., in this publication, even if the former are not especially identified, is not to be taken as a sign that such names, as understood by the Trade Marks and Merchandise Marks Act, may accordingly be used freely by anyone.

Production coordinated by Chernow Editorial Services, Inc., and managed by Francine McNeill; manufacturing supervised by Erica Bresler.

Typeset by Matrix Publishing Services, Inc., York, PA.

Printed and bound by Maple-Vail Book Manufacturing Group, York, PA.

Printed in the United States of America.

9876554321

ISBN 0-387-98801-7 Springer-Verlag New York Berlin Heidelberg SPIN 10715990 
To the Memory of My Dad 


\section{Preface}

"The human body is a machine whose movements are directed by the soul," wrote René Descartes in the early seventeenth century. The intrinsic mechanisms of this machine gradually became clear through the hard work of Renaissance scientists. Leonardo da Vinci is one such scientist from this period of enlightenment. In pursuit of knowledge, Leonardo dissected the bodies of more than 30 men and women. He sawed the bones lengthwise, to see their internal structure; he sawed the skull, cut through the vertebrae, and showed the spinal cord. In the process, he took extensive notes and made carefully detailed sketches. His drawings differentiated muscles that run across several joints from those muscles that act on a single joint. "Nature has made all the muscles appertaining to the motion of the toes attached to the bone of the leg and not to that of the thigh," wrote Leonardo in 1504 next to one of his sketches of the lower extremity, "because when the knee joint is flexed, if attached to the bone of the thigh, these muscles would be bound under the knee joint and would not be able to serve the toes. The same occurs in the hand owing to the flexion of the elbow."

Another Renaissance scholar who made fundamental contributions to the physiology of movement is Giovanni Alfonso Borelli. Born in 1604 in Naples, Borelli was a well-respected mathematician. While teaching at the University of Pisa, he collaborated with the faculty of theoretical medicine in the study of movement. Borelli showed that muscles and bones formed a system of levers. He showed that during some physical activity the hip and the knee transmit forces that are several times greater than the body weight. He spent many years trying to secure funding for the publication of his masterpiece On the Movement of Animals. Borelli died in 1679, a few weeks after Queen Catherine of Sweden agreed to pay for the publication costs of the book. The first volume of On the Movement of Animals was published the following year.

The advances in the understanding of human body structure and its relation to movement were soon followed by the formulation of nature's laws of motion. In his groundbreaking book Philosophie Naturalis Principia 
Mathematica, published in 1687, Sir Isaac Newton presented these laws in mathematical language. The laws of motion can be summarized as follows: A body in our universe is subjected to a multitude of forces exerted by other bodies. The forces exchanged between any two bodies are equal in magnitude but opposite in direction. When the forces acting on a body balance each other, the body either remains at rest or, if it were in motion, moves with constant velocity. Otherwise, the body accelerates in the direction of the net unbalanced force.

Newton's contributions to mechanics were built on the wealth of knowledge accumulated by others. In this regard, perhaps the most critical advances were made by Galileo Galilei. Born in Italy on February 15, 1564, Galileo became fascinated with mathematics while studying medicine at the University of Pisa. At the university, he was perceived as an arrogant young man. He made many enemies with his defiant attitude toward the Aristotelian dogma and had to leave the university for financial reasons without receiving a degree. Galileo recognized early on the importance of experiments for advancing science. He observed that, for small oscillations of a pendulum, the period of oscillation was independent of the amplitude of oscillation. This discovery paved the way for making mechanical clocks. One of his stellar contributions to mechanics is the law of free fall. Published first in his 1638 book Discorsi, the law states that in a free fall distances from rest are proportional to the square of elapsed times from rest. Although Galileo found recognition and respect in his lifetime, he was nonetheless sentenced to prison at the age of 70 by the Catholic Church for having held and taught the Copernican doctrine that the Earth revolves around the Sun. He died while under house arrest.

Newton's laws were written for so-called particles, however large they may be. A particle is an idealized body for which the velocity is uniform within the body. In the eighteenth century, Leonhard Euler, Joseph-Louis Lagrange, and others generalized these laws to the study of solid bodies and systems of particles. Euler was the first to assign the same gravitational force to a body whether at rest or in motion. In 1760, his work Thoria Motus Corporum Solidurum seu Rigidorum described a solid object's resistance to changes in the rate of rotation. A few years later, in 1781, Charles-Augustin de Coulomb formulated the law of friction between two bodies: "In order to draw a weight along a horizontal plane it is necessary to deploy a force proportional to the weight . . . ." Coulomb went on to discover one of the most important formulas in physics, that the force between two electrical charges is inversely proportional to the square of the distance between them. Analytical developments on solid mechanics continued with the publication in 1788 of Lagrange's elegant work Mechanic Analytique.

The foundation of classical mechanics set the stage for further studies of human and animal motion. "It seems that, as far as its physique is concerned, an animal may be considered as an assembly of particles sepa- 
rated by more or less compressed springs," wrote Lazare Carnot in 1803. In the 1880s, Eadweard Muybridge in America and Ettiene-Jules Marey in France established the foundation of motion analysis. They took sequential photographs of athletes and horses during physical activity to gain insights into movement mechanics. Today, motion analysis finds particular use in physical education, professional sports, and medical diagnostics. Recent research suggests that the video recording of crawling infants may be used to diagnose autism at an early stage.

The sequential photography allows for the evaluation of velocities and accelerations of body segments. The analysis of forces involved in movement is much more challenging, however, because of the difficult mathematics of classical mechanics. To illustrate the point, scientists were intrigued in the nineteenth century about the righting movements of a freely falling cat. How does a falling cat turn over and fall on its feet? M. Marey and M. Guyou addressed the issue in separate papers published in Paris in 1894. About 40 years later, in 1935, G.G.J. Rademaker and J.W.G. Ter Braak came up with a mathematical model that captured the full turnover of the cat during a fall. The model was refined in 1969 by T.R. Kane and M.P. Schmer so that as observed in the motion of the falling cat the predicted backward bending would be much smaller than forward bending. The mechanism presented by Kane and Schmer is simple; it consists of two identical axisymmetric bodies that are linked together at one end. These bodies can bend relative to each other but do not twist. Space scientists found the model useful in teaching astronauts how to move with catlike ease in low gravity.

Although the mechanical model of a falling cat is simple conceptually, its mathematical formulation and subsequent solution are quite challenging. Since the development of the falling cat model, computational advances have made it easier to solve the differential equations of classical mechanics. Currently, there are a number of powerful software packages for solving multibody problems. Video recording is used to quantify complex modes of movement. Present technology also allows for the measurement of contact forces and the evaluation of the degree of activation of muscle groups associated with motion. Nowadays, the data obtained on biomechanics of movement can be overwhelming. A valid interpretation of the data requires an in-depth understanding of the laws of motion and the complex interplay between mechanics and human body structure. The main goal of this book is to present the principles of classical mechanics using case studies involving human movement. Unlike nonliving objects, humans and animals have the capacity to initiate movement and to modify motion through changes of shape. This capability makes the mechanics of human and animal movement all the more exciting.

I believe that Human Body Dynamics will stimulate the interests of engineering students in biomechanics. Quantitative studies of human movement bring to light the healthcare-related issues facing classical mechan- 
ics in the twenty-first century. There are already a number of outstanding statics and dynamics books written for engineering students. In recent years, with each revision, these books have incorporated more examples, more problems, and more colored photographs and figures, a few of which touch on the mechanics of human movement. Nevertheless, the focus of these books remains almost exclusively on the mechanics of manmade structures. It is my hope that Human Body Dynamics exposes the reader not only to the principles of classical mechanics but also to the fascinating interplay between mechanics and human body structure.

The book assumes a background in calculus and physics. Vector algebra and vector differentiation are introduced in the text and are used to describe the motion of objects. Advanced topics such as three-dimensional motion mechanics are treated in some depth. Whenever possible, the analysis is presented graphically using schematic diagrams and softwarecreated sequences of human movement in an athletic event or a dance performance. Each chapter contains illustrative examples and problem sets. I have spent long days in the library reading scientific journals on biomechanics, sports biomechanics, orthopaedics, and physical therapy so that I could conceive realistic examples for this book. The references included provide a list of sources that I used in the preparation of the text. The book contains mechanical analysis of dancing steps in classical ballet, jumping, running, kicking, throwing, weight lifting, pole vaulting, and three-dimensional diving. Also included are examples on crash mechanics, orthopaedic techniques, limb-lengthening, and overuse injuries associated with running.

Although the emphasis is on rigid body mechanics and human motion, the book delves into other fundamental topics of mechanics such as deformability, internal stresses, and constitutive equations. If Human Body Dynamics is used as a textbook for a graduate-level course, I would recommend that student projects on sports biomechanics and orthopaedic engineering become an integral part of the course. The references cited at the end of the text provide a useful guide to the wealth of information on the biomechanics of movement.

Human Body Dynamics should be of great interest to orthopaedic surgeons, physical therapists, and professionals and graduate students in sports medicine, movement science, and athletics. They will find in this book concise definitions of terms such as linear momentum and angular velocity and their use in the study of human movement.

I wish to acknowledge my gratitude to all authors on whose work I have drawn. My colleagues and students at The Catholic University of America helped me refine my teaching skills in biomechanics. Professor Van Mow provided me with generous resources during my sabbatical at Columbia University where I prepared most of the text. I am deeply indebted to Professor H. Bülent Atabek of The Catholic University of America for his careful reading of the manuscript. Professor Atabek corrected 
countless equations and figures and provided valuable input to the contents of the manuscript. My teachers, Professors Maciej P. Bieniek and Frank L. DiMaggio of Columbia University, also spent considerable time reviewing the manuscript. I am very grateful to them for their corrections and constructive suggestions. Dr. Rukmini Rao Mirotznik enriched the text with her beautiful sketches and sublime figures. Barbara A. Chernow and her associates contributed to the book with careful editing and outstanding production. Finally, my thanks goes to Dr. Robin Smith and his associates at Springer-Verlag for bringing this book to life.

Washington, D.C.

AYDIN TÖZEREN 


\section{Contents}

Preface $\ldots \ldots \ldots \ldots \ldots \ldots \ldots \ldots \ldots \ldots \ldots \ldots \ldots \ldots \ldots \ldots$ vii

Nomenclature ........................ xvii

\section{Chapter 1 Human Body Structure}

Muscles, Tendons, Ligaments, and Bones $\ldots \ldots \ldots \ldots \ldots \ldots .1$

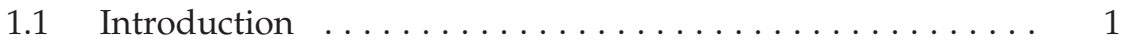

1.2 Notation for Human Movement . . . . . . . . . . . . . . 3

1.3 Skeletal Tree ........................ 6

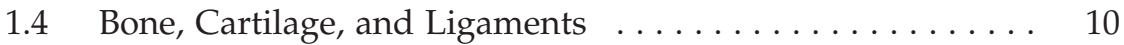

1.5 Joints of the Human Body . . . . . . . . . . . . . . . . 14

1.6 Physical Properties of Skeletal Muscle . . . . . . . . . . 17

1.7 Muscle Groups and Movement . . . . . . . . . . . . . . 21

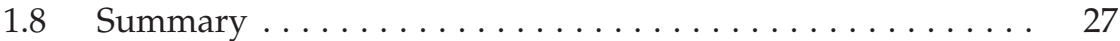

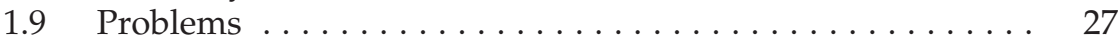

Chapter 2 Laws of Motion

Snowflakes, Airborne Balls, Pendulums .............. 30

2.1 Laws of Motion: A Historical Perspective ........... 30

2.2 Addition and Subtraction of Vectors ............ 33

2.3 Time Derivatives of Vectors . . . . . . . . . . . . . . 39

2.4 Position, Velocity, and Acceleration ............. 40

2.5 Newton's Laws of Motion and Their Applications ........ 43

2.6 Summary .......................... 52

2.7 Problems . . . . . . . . . . . . . . . . . . . . 53 


\section{Chapter 3 Particles in Motion}

Method of Lumped Masses and Jumping, Sit-Ups, Push-Ups . . . 56

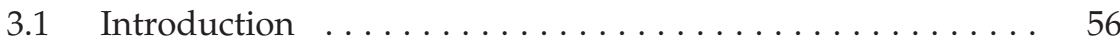

3.2 Conservation of Linear Momentum . . . . . . . . . . 57

3.3 Center of Mass and Its Motion . . . . . . . . . . . . . . . 58

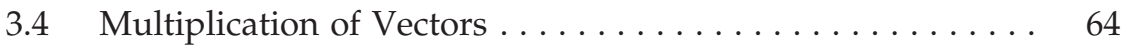

3.5 Moment of a Force . . . . . . . . . . . . . . . 67

3.6 Moment of Momentum About a Stationary Point ... . . . 70

3.7 Moment of Momentum About the Center of Mass ... . . . . 77

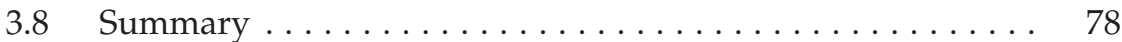

3.9 Problems ............................. 79

Chapter 4 Bodies in Planar Motion Jumping, Diving, Push-Ups, Back Curls . . . . . . . . . . . . . . . 84

$4.1 \quad$ Introduction $\ldots \ldots \ldots \ldots \ldots \ldots \ldots \ldots \ldots \ldots$

4.2 Planar Motion of a Slender Rod . . . . . . . . . . . 85

4.3 Angular Velocity ........................ 88

4.4 Angular Acceleration $\ldots \ldots \ldots \ldots \ldots \ldots \ldots . \ldots . \ldots . \ldots 9$

4.5 Angular Momentum . . . . . . . . . . . . . . . . 97

4.6 Conservation of Angular Momentum . . . . . . . . . . . . 100

4.7 Applications to Human Body Dynamics . . . . . . . . . . . 103

4.8 Instantaneous Center of Rotation . . . . . . . . . . . . . . 109

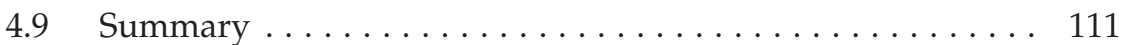

4.10 Problems ........................... 112

Chapter 5 Statics

Tug-of-War, Weight Lifting, Trusses, Cables, Beams . . . . . . . . 117

$5.1 \quad$ Introduction $\ldots \ldots \ldots \ldots \ldots \ldots \ldots \ldots \ldots \ldots \ldots \ldots \ldots \ldots$

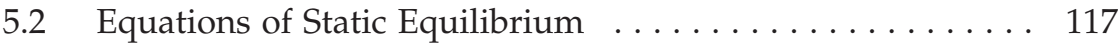

5.3 Contact Forces in Static Equilibrium . . . . . . . . . . . . 121

5.4 Structural Stability and Redundance . . . . . . . . . . . . 127

5.5 Structures and Internal Forces . . . . . . . . . . . . . . . . 135

5.6 Distributed Forces . . . . . . . . . . . . . . . . . . . 144

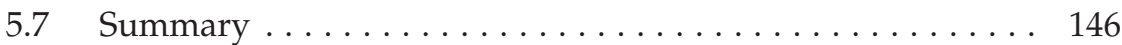

5.8 Problems . . . . . . . . . . . . . . . . . . . . . 146 
Chapter 6 Internal Forces and the Human Body

Complexity of the Musculoskeletal System . . . . . . . . . . . . 150

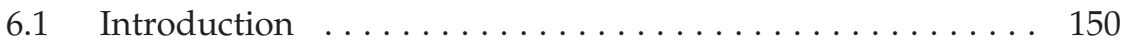

6.2 Muscle Force in Motion . . . . . . . . . . . . . . . . . 152

6.3 Examples from Weight Lifting . . . . . . . . . . . . . 157

6.4 Moment Arm and Joint Angle ............... 161

6.5 Multiple Muscle Involvement in Flexion of the Elbow . . . . . 164

6.6 Biarticular Muscles . . . . . . . . . . . . . . . . . . . . 165

6.7 Physical Stress . . . . . . . . . . . . . . . . . . . . . . . . . . . 169

6.8 Musculoskeletal Tissues . . . . . . . . . . . . . . . . 172

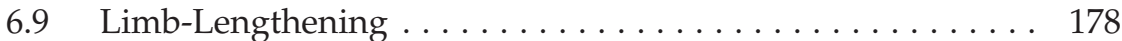

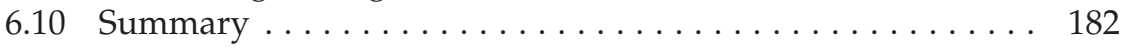

6.11 Problems ......................... 183

Chapter 7 Impulse and Momentum

Impulsive Forces and Crash Mechanics . . . . . . . . . . . . . . . 194

$7.1 \quad$ Introduction . . . . . . . . . . . . . . . . . . . 194

$7.2 \quad$ Principle of Impulse and Momentum . . . . . . . . . . . . . . . 194

7.3 Angular Impulse and Angular Momentum . . . . . . . . . 200

7.4 Elasticity of Collision: Coefficient of Restitution . . . . . . . . 207

7.5 Initial Motion . . . . . . . . . . . . . . . . . . . 211

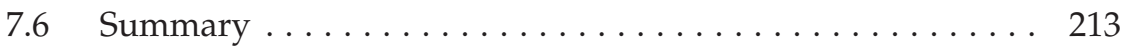

7.7 Problems . . . . . . . . . . . . . . . . . . . 214

Chapter 8 Energy Transfers

In Pole Vaulting, Running, and Abdominal Workout . . . . . . . 220

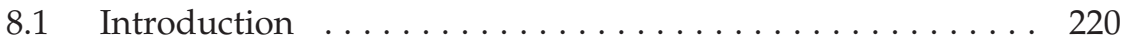

8.2 Kinetic Energy . . . . . . . . . . . . . . . . . . . . . . 221

8.3 Work ........................... 225

8.4 Potential Energy $\ldots \ldots \ldots \ldots \ldots \ldots \ldots \ldots \ldots \ldots \ldots \ldots$

8.5 Conservation of Mechanical Energy _. . . . . . . . . . . . 230

8.6 Multibody Systems . . . . . . . . . . . . . . . . . 232

8.7 Applications to Human Body Dynamics . . . . . . . . . . 235

8.8 Summary . . . . . . . . . . . . . . . . . . . . . 246

8.9 Problems . . . . . . . . . . . . . . . . . . . . . 247 


\section{Chapter 9 Three-Dimensional Motion}

Somersaults, Throwing, and Hitting Motions . . . . . . . . . . . 256

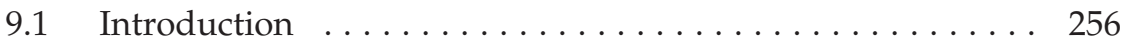

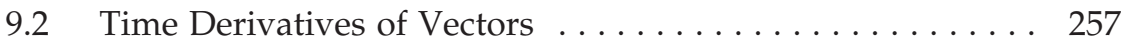

9.3 Angular Velocity and Angular Acceleration ............ 258

9.4 Conservation of Angular Momentum . . . . . . . . . . . . 264

9.5 Dancing Holding on to a Pole . ............... 271

9.6 Rolling of an Abdominal Wheel on a Horizontal Plane . . . 275

9.7 Biomechanics of Twisting Somersaults . . . . . . . . . . . 280

9.8 Throwing and Hitting Motions . . . . . . . . . . . . 283

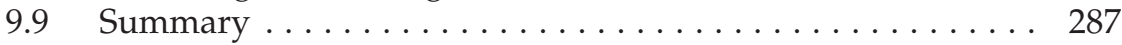

9.10 Problems . . . . . . . . . . . . . . . . . . . . . . . . . 289

Appendix 1 Units and Conversion Factors _. . . . . . . . . . . 297

Appendix 2 Geometric Properties of the Human Body . . . . . . 299

Selected References . . . . . . . . . . . . . . . . . . . . . . . . . . 304

Index ............................ 311 


\section{Nomenclature}

${ }^{R} \mathbf{a}^{P}$ : Acceleration of point $P$ in reference frame $R\left(\mathrm{~m} / \mathrm{s}^{2}\right)$

$\alpha^{P}=E_{\mathbf{a}} P$ : Acceleration of point $P$ in the reference frame $E$, which is fixed on earth

$a^{c}$ : Acceleration of the center of mass of a body in the inertial reference frame $E$

$\alpha$ : Angular acceleration of body $B$ in reference frame $E(1 / \mathrm{s})$

$B$ : Represents a body with volume $V$ and mass $m$

$\mathbf{b}_{1}, \mathbf{b}_{2}, \mathbf{b}_{2}$ : Orthogonal unit vectors associated with body $B$

$C$ : Center of mass

$d \mathbf{a} / d t$ : Time derivative of a

$d^{2} \mathbf{a} / d t^{2}$ : Second time derivative of a

$E$ : Reference frame fixed on earth

$E$ : Young's modulus for elastic materials $\left(\mathrm{N} / \mathrm{m}^{2}\right)$

$\epsilon$ : Strain, ratio of change in length to stress-free length of a line element

$\mathbf{e}_{1}, \mathbf{e}_{2}, \mathbf{e}_{2}$ : Orthogonal unit vectors defining the reference frame $E$

F: Force $(\mathrm{N})$

$\mathbf{f}_{i j}$ : Force exerted by mass element $j$ on the mass element $i$ within a body $B$ (system of particles)

g: Gravitational acceleration $\left(\mathrm{m} / \mathrm{s}^{2}\right)$

$\mathbf{H}^{c}$ : Moment of momentum of a body (system of particles) about a point $C$

$\mathbf{H}^{0}$ : Moment of momentum of a body (system of particles) about a point $\mathrm{O}\left(\mathrm{kg}-\mathrm{m}^{2} / \mathrm{s}\right)$

$I_{i j}$ : $i j$ th component of mass moment of inertia about the center of mass $\left(\mathrm{kg}-\mathrm{m}^{2}\right)$

$I_{i j:}^{o}$ ijth component of mass moment of inertia about point $O$

$J_{x}$ : Axial moment of inertia $\left(\mathrm{m}^{4}\right)$

$k$ : Spring constant $(\mathrm{N} / \mathrm{m})$

$k$ : Radius of gyration $(\mathrm{m})$

$\Lambda$ : Angular impulse (N-m-s)

L: Linear momentum of a particle, body, or system of particles $(\mathrm{kg}-\mathrm{m} / \mathrm{s})$ $\mathbf{M}^{o}$ : Moment of a force about point $O(\mathrm{~N}-\mathrm{m})$ 
$m$ : Mass of a particle or a body $(\mathrm{kg})$

$\mu$ : Coefficient of friction

$P$ : Mechanical power (rate of work done by a system of forces) $(\mathrm{N}-\mathrm{m} / \mathrm{s})$ $\mathbf{r}^{P / O}$ : Position vector connecting point $O$ to point $P(m)$

$\rho$ : Position vector connecting the center of mass of a body to a point of the body

$\sigma$ : Stress, force intensity, force per unit area $\left(\mathrm{N} / \mathrm{m}^{2}\right)$

$t$ : Time

T: Kinetic energy (N-m)

$T$ : Tension in a cable, tendon, or ligament $(\mathrm{N})$

$V$ : Potential energy $(\mathrm{N}-\mathrm{m})$

$V$ : Rate of shortening, ratio of rate of change of length to the length of a muscle fiber $(1 / \mathrm{s})$

${ }^{R} \mathbf{v}^{P}$ : Velocity of point $P$ in reference frame $R(\mathrm{~m} / \mathrm{s})$

$\mathbf{v}^{P}={ } \mathbf{v}^{P}$ : Velocity of point $P$ in the reference frame $E$, which is fixed on earth

$W$ : Work done on a system by a force $(\mathrm{N}-\mathrm{m})$

$w$ : Load per unit area (length) that is acting on a structure $\left(\mathrm{N} / \mathrm{m}^{2}\right.$ or N $\left./ \mathrm{m}\right)$ ${ }^{R} \omega^{B}$ : Angular velocity of rigid body $B$ in reference frame $R(1 / \mathrm{s})$

$\omega$ : Angular velocity of body $B$ in reference frame $E$

$\zeta$ : Impulse (N-s)

Notes: The terms in parentheses present the units of each variable. The abbreviations $\mathrm{kg}, \mathrm{m}, \mathrm{N}$, and s stand, respectively, for kilogram, meter, Newton, and second. In general, a left superscript refers to a reference frame under consideration. For simplicity, we omit the superscript when the reference frame is one that is fixed on Earth. A right superscript may indicate a point or a body. Frequently, we omit this superscript when the text clearly indicates which point or body is being referred to. The subscripts typically indicate a component along a certain coordinate axis. 